\title{
BANCOS FORRAGEIROS COM GRAMÍNEAS E LEGUMINOSAS NO ASSENTAMENTO BELO HORIZONTE, SÃO DOMINGOS DO ARAGUAIA $-\mathbf{P A}$
}

\author{
Dayanne Lustosa Mororón ; Alzira Gabriela da Silva ${ }^{2}$ \\ ${ }^{1}$ Discente do Curso de Agronomia, Faculdade de Ciências Agrárias de Marabá (FCAM), Universidade Federal do Pará \\ (UFPA), Marabá, Pará. Bolsista PIBEX. E-mail: dayanne_mba@hotmail.com. \\ ${ }^{2}$ Zootecnista, Prof. ${ }^{\text {a }, ~ M . S c ., ~ F C A M, ~ U F P A . ~ E-m a i l: ~ a l z i r a g a b i @ u f p a . b r . ~}$
}

RESUMO: Na tentativa de melhorar a qualidade da alimentação animal no Projeto de Assentamento Belo Horizonte, localizado no município de São Domingos do Araguaia-Pará, realizou-se a difusão da prática da introdução de bancos forrageiros. As atividades serão desenvolvidas através da abordagem participativa e da pesquisa-ação. $\mathrm{O}$ objetivo deste trabalho é difundir o uso de bancos forrageiros de alta qualidade com leguminosas e gramíneas visando à introdução dos mesmos nos sistemas de criação de bovinos leiteiros já praticados, melhorando a qualidade da alimentação animal durante o período seco do ano, na agricultura familiar no Sudeste do Estado do Pará. Serão realizadas no projeto seis fases, onde irão compreender a apresentação do programa, a capacitação dos produtores e implantação bancos escolhidos, a avaliação e levantamento de dados da produtividade e/o crescimento das espécies utilizadas no banco forrageiro e a viabilidade econômica e ainda será proposto à criação de uma associação ou cooperativa com a finalidade de facilitar a aquisição de insumos e a comercialização de produtos no âmbito de melhorar as articulações dos produtores.

PALAVRAS CHAVES: Agricultura familiar, bovinocultura leiteira, extensão rural, proteína bruta. 